\title{
COASTLINE ZONE EXTRACTION USING LANDSAT-8 OLI IMAGERY, CASE STUDY: BODRUM PENINSULA, TURKEY
}

\author{
T. Isiacik Colak ${ }^{1 *}$, G. Senel ${ }^{2}$, C. Goksel ${ }^{3}$ \\ ${ }^{1}$ Istanbul Technical University, Institute of Informatics, Satellite Communications Remote Sensing, 34469 Maslak-Istanbul, Turkey \\ ${ }^{2}$ Istanbul Technical University, Institute of Science and Technology, Geomatics Engineering, 34469 Maslak-Istanbul, Turkey \\ (gizemsene194@gmail.com) \\ ${ }^{3}$ Istanbul Technical University Department of Geomatics Engineering, 34469 Maslak-Istanbul, Turkey - (goksel@itu.edu.tr.)
}

KEY WORDS: Remote sensing, coastline extraction, Landsat-8 OLI, water index, AWEI

\begin{abstract}
:
Coastline extraction is a fundamental work for coastal resource management and coastal environmental protection. Today, by using digital image processing techniques, coastline extraction can be done with remote sensing imagery systems. In this study, Landsat 8 Operational Land Imagery (OLI) data have been the main data source due to free access and sufficient spatial resolution for coast line extraction. This research is focused on determining the coastline length and measuring land area by using Landsat 8 OLI satellite image for Bodrum Peninsula, Turkey. Three commonly used methods have been applied in order to determine sea-land boundary line and its length, and area of the study area. The Automatic Water Extraction Index (AWEI), Iterative Self-Organizing Data Analysis Technique (ISODATA) unsupervised classification technique and on screen digitizing method was chosen for identification of coastal boundaries. Results of coastline length and land areas of Bodrum by using AWEI, ISODATA and on-screen digitizing are compared with each other. This study shows that with using optimal threshold value, AWEI can be used for coast line extraction method with coherently for Landsat 8 OLI satellite imagery. The overall results show that coastline extraction from satellite imagery can be done with sufficient accuracy using spectral water indices instead of time consuming on-screen digitizing.
\end{abstract}

\section{INTRODUCTION}

The coastline which has a dynamic nature refers to the most important line features on earth's surface (Alesheikh et al., 2007; Winarso et al., 2001). Monitoring coastline changes in time is essential to provide fundamental information about the situation that the environment in; due to this reason it is necessary to monitor the coastline dynamics with large spatial scales and for long time periods (Xu, 2018; Lui et al., 2017; Papakonstantinou et al., 2016). Calibrating and verifying numerical models (Kraus, 1988), assessment of sea level rise (Leatherman, 2001), identification of legal property boundaries (Morton and Speed, 1998) and coastal survey-monitoring (Smith and Jackson, 1992) are examples of coastline investigations conducted (Boak and Turner, 2005). This task is difficult, time consuming, and sometimes impossible for a large area when traditional ground survey techniques are used (Cracknel, 1999). Alternatively, remotely sensed data provide important preliminary estimates of change. Although maps provide good spatial coverage, they are limited for temporal resolution and location (Dolan et al., 1983). Remote sensing technology provides continuous monitoring of shorelines and it is a very important source for detection of changes in coastlines (Kevin and El-Asmar, 1999). Multispectral imaging systems such as Landsat and Sentinel series provide broad spectral, spatial and temporal resolution. Coastline can be obtained by on screen digitizing features (using true or false colour images) or by using digital image processing techniques. There are numerous digital image processing techniques that allow extraction of coastline and mapping.
Density slicing methods for coastline delineation using single band Landsat TM; multiband methods to extract the water area (Du., Z., et al 2012; Mc Feeter, 1996; Xu, 2006; Wang et al, 2017; Feyisa et al, 2014) band rationing (Alesheikh et al., 2007; Niya et al, 2013) classification (Gurglia et al 2006; Ekercin 2007; Garcia et al., 2015) on screen digitizing (Goksel et al, 2001; Sameh et al, 2017; Niya et al., 2013) are methods to identify coastline from multispectral satellite images.

This study investigates extraction coastline of Bodrum Peninsula with using three commonly used techniques; Automatic Water Extraction Index (AWEI) (Feyisa et al., 2014; Xia et al., 2018; Liu et al., 2017) Iterative Self-Organizing Data Analysis Technique (ISODATA) unsupervised classification technique (Papakonstantinou et al., 2016) and on screen digitizing method in order to determine land-sea boundary line and its length, and area of the Bodrum Peninsula. Results of coastline length and land areas of Bodrum by using AWEI, ISODATA and on-screen digitizing are compared with each other.

\section{STUDY AREA AND DATA SETS}

The study area of this research is Bodrum Peninsula which is in the Muğla, Turkey (Figure 1). The coast of the province is very indented and protruding, it consists of areas with a lot of limestone content due to its soil structure.

The district is located on a peninsula between Gulluk in the north and Gokova Gulf in the south. Satellite image is dated to 11 September 2017 for Landsat 8 OLI.

\footnotetext{
* Corresponding author Email: isiacik@itu.edu.tr.
} 

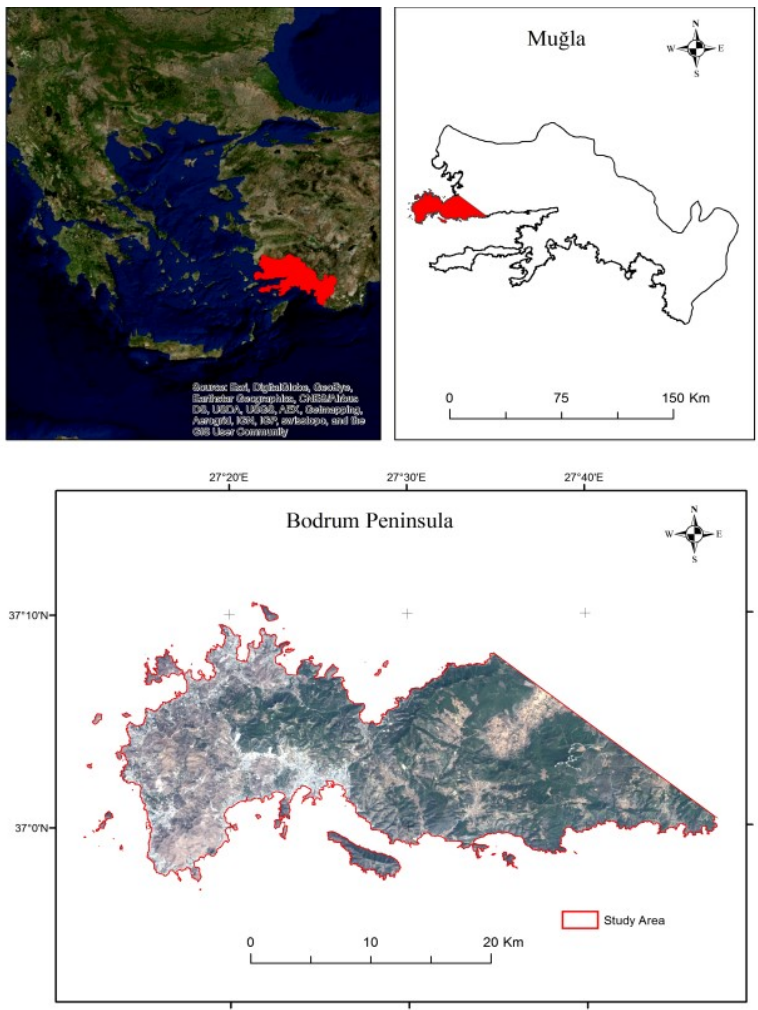

Figure 1. Study Area

\subsection{Data Sets}

In this study, $1 / 50,000$ scaled conventional maps and Landsat 8 OLI satellite data are used. Six bands of the Landsat 8 satellite images were used in the study, blue, green, red, near infrared (NIR), shortwave infrared 1(SWIR 1) and shortwave infrared 2 (SWIR 2). The characteristics of the corresponding bands used in the study are presented in Table 1. The programs used are ArcGIS 10.2.1, ENVI 5.2 and ERDAS Imagine 2014.

\begin{tabular}{|c|c|c|c|c|}
\hline \multirow{7}{*}{$\begin{array}{l}\text { Landsat } 8 \\
\text { Operational } \\
\text { Land } \\
\text { Imager } \\
\text { (OLI) }\end{array}$} & Bands & $\begin{array}{l}\text { Wavelength } \\
(\mu \mathrm{m})\end{array}$ & $\begin{array}{l}\operatorname{Res} \\
(m)\end{array}$ & Area of Use \\
\hline & Band 2 - Blue & $0.452-0.512$ & 30 & $\begin{array}{l}\text { bathymetric } \\
\text { mapping, }\end{array}$ \\
\hline & Band 3 - Green & $0.533-0.590$ & 30 & $\begin{array}{l}\text { to evaluate } \\
\text { plant health. }\end{array}$ \\
\hline & Band 4 - Red & $0.636-0.673$ & 30 & $\begin{array}{l}\text { distinguish } \\
\text { vegetation } \\
\text { trends }\end{array}$ \\
\hline & $\begin{array}{l}\text { Band } 5 \text { - Near } \\
\text { Infrared (NIR) }\end{array}$ & $0.851-0.879$ & 30 & $\begin{array}{l}\text { biomass } \\
\text { content and } \\
\text { coastline }\end{array}$ \\
\hline & $\begin{array}{l}\text { Band } 6 \text { - } \\
\text { Shortwave } \\
\text { Infrared } \\
\text { (SWIR) } 1\end{array}$ & $1.566-1.651$ & 30 & $\begin{array}{l}\text { Distinguish } \\
\text { the soil's } \\
\text { moisture } \\
\text { content. }\end{array}$ \\
\hline & $\begin{array}{l}\text { Band } 7 \text { - } \\
\text { (SWIR) } 2\end{array}$ & $2.107-2.294$ & 30 & $\begin{array}{l}\text { Moisture } \\
\text { vegetation }\end{array}$ \\
\hline
\end{tabular}

Table 1. Landsat 8 Operational Land Imager (OLI) Sensor

\section{MATERIAL AND METHODS}

Using the Landsat 8 OLI satellite image, the area calculation of the peninsula and coastline length are determined using different methods. The process steps are expressed in Figure 2.

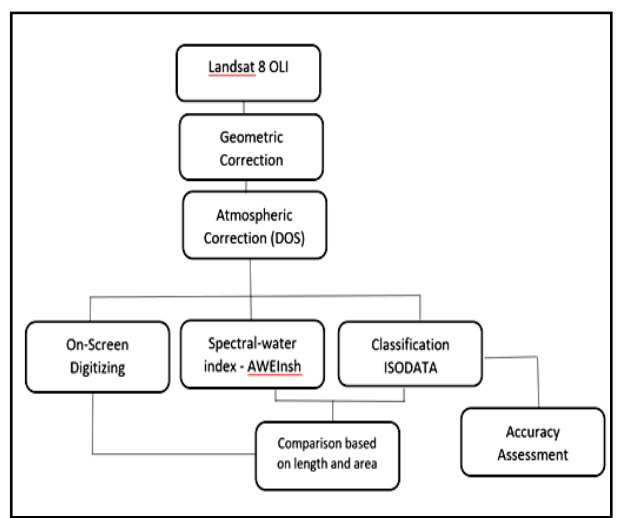

Figure 2. Flowchart of the method

\subsection{Pre-processing}

3.1.1 Geometric Correction: Landsat 8 OLI image was rectified and projected using Universal Transverse Mercator (UTM) coordinate system in the World Geodetic System 1984 (WGS 84) datum. A second order polynomial transform was used to model the geometric distortions in the satellite image data. ArcMap IKONOS base map with a spatial resolution of 5 $\mathrm{m}$ was used as reference. Geometric correction was made using 31 ground control points. Registration error of image was found as $0.5 \mathrm{~m}$ pixel.

3.1.2 Atmospheric Correction: Dark Object Extraction (DOS) was used to remove the effect of atmospheric scattering. DOS is a simple empirical atmospheric correction method for satellite images. It assumes that reflectance from dark objects includes a substantial component of atmospheric scattering. Dark Subtraction is used to remove the effects of atmospheric scattering from the image by subtracting a pixel value that represents a background signature from each band. With subtracting this value from every pixel in the band, the scattering is removed (Crane, 1971).

\subsection{Image Processing}

The extraction of information with remote sensing data has always been an important study area (Hu et al., 2008). In this framework, AWEI, ISODATA unsupervised classification and on-screen digitizing image processing techniques was evaluated and compared for coastline extraction from Landsat 8 OLI data.

3.2.1 Index: AWEI (Automatic Water Extraction Index) index is used in the study. The main objective of the AWEI is to distinguish between water and non-water pixels; taking the difference of bands, collecting bands and maximizing using coefficients. AWEI is formulated to effectively isolate nonwater pixels, including dark, built-up surfaces with urban background (Feyisa et al, 2014). The coefficients used in these equations aim to maximize the separability of water and nonwater surfaces in low reflectance. AWEInsh is mainly effective to eliminate non -water pixel areas and used in areas with an urban background, while AWEIsh is formulated with further accuracy to remove shadow pixels that AWEInsh may not effectively eliminate. AWEInsh which is expressed in equation 1 used in this study (Feyisa et al, 2014).

$\mathrm{AWEInsh}=4 \times($ Green $-\mathrm{SWIR} 1)-(0.25 \times \mathrm{NIR}+2.75 \times$ SWIR2)

Equation 1 
3.2.2 On Screen Digitizing: Extraction of shoreline by on screen digitizing is easy and costless method. This method is used to extract shoreline by digitization of a shoreline from an available geo-information. In this method the shoreline has been drawn as a line at intersection between water and lands by the operator manually and all relevant map objects are vectorized. An improved accuracy can be achieved by zooming properties and digitizing by same analyst. The disadvantage of this method is to be time consuming. In this study the scale was selected as 1:2000 as possible.

3.2.3 ISODATA Unsupervised Classification: The Iterative Self-Organizing Data Analysis Technique (ISODATA) is an unsupervised classification algorithm. In this study ISODATA classification method was used to classify into 200 classes and generalized to 2 clusters as water and non-water. For the accuracy assessment process, 100 randomly stratified sample point was created in ArcMap software. Overall accuracy was calculated for accuracy assessment.

\section{RESULTS AND CONCLUSION}

Three different methods of coast line extraction were applied to Landsat 8 OLI Bodrum Peninsula images. The comparison of AWEI, on screen digitizing and ISODATA Unsupervised classification were done.

ISODATA classification regrouped into only two classes as water and non-water area. Overall accuracy was achieved over $85 \%$. The land-sea boundary line resulting from water-nonwater obtained from the classification has been converted into vector data. On screen digitizing method is reference for this study while calculating the coastline length. Comparison of AWEI and ISODATA can be seen in the Table 2, Table 3 and Figure 3.

When the on screen digitizing data were used as reference data, the area difference for AWEI was found to be 63.15 hectares $(0.1 \%)$ and 236.65 hectares $(0.4 \%)$ for the classification results. Also, length difference for AWEI was found as $9.339 \mathrm{~km}$ $(3.5 \%)$ and for classification results was found as $16.252 \mathrm{~km}$ (6.1\%).

Study area does not have a smooth boundary and ISODATA classification could not detect the boundary properly. The total coastline length of Bodrum Peninsula was calculated shorter than the two methods by ISODATA classification.

\begin{tabular}{|c|c|c|c|}
\hline & $\begin{array}{c}\text { On-screen } \\
\text { digitizing } \\
\text { (Reference) }\end{array}$ & AWEI & ISODATA \\
\hline Area $(\mathrm{km})$ & 266,267 & 256,928 & 250,015 \\
\hline $\begin{array}{c}\text { Difference } \\
(\mathrm{km})\end{array}$ & & 9,339 & 16,252 \\
\hline $\begin{array}{c}\text { Difference } \\
(\%)\end{array}$ & & 3.5 & 6.1 \\
\hline
\end{tabular}

Table 2. Areal difference results

\begin{tabular}{|c|c|c|c|}
\hline & $\begin{array}{c}\text { On-screen } \\
\text { digitizing } \\
\text { (Reference) }\end{array}$ & AWEI & ISODATA \\
\hline Area (ha) & $57,902.75$ & $57,839.60$ & $57,666.10$ \\
\hline $\begin{array}{c}\text { Difference } \\
\text { (ha) }\end{array}$ & & 63.15 & 236.65 \\
\hline $\begin{array}{c}\text { Difference } \\
(\%)\end{array}$ & 0.1 & 0.4 \\
\hline
\end{tabular}

Table 3. Length difference results

Manual on screen digitizing method process is time consuming than the other methods and needs analyst expert but on screen digitizing method has high accuracy. The reason of good result of AWEI is attributed to the special characteristic of the water that absorbs more MIR light than the NIR light. In threshold algorithm, pixel water with values equal to or greater than the specified threshold value is classified as water, while in other cases the pixel is classified as water-free. After the AWEI index was converted from the raster to the vector, the coastal indentations were more accurately detected. A carefully selected threshold application is required for application. One of the problem of AWEInsh is determination of ideal threshold value. In addition to above mentioned, the discrimination capability of coast and sea is not sufficient due to medium spatial resolution when comparing with on screen digitizing method for small scale studies. Due to indented shape of Bodrum Peninsula, in some regions, the continuation of the rock fragments under water leads causes calculation of the coastal area more than real for on screen digitizing method and AWEI method. The seafacing side of the rock fields, which appear to be cut with some straight knife, makes the pixels look darker. In addition, many small berths and small wharves belonging to the marinas in the Bodrum Peninsula could not be detected even on screen digitizing method due to medium spatial resolution.

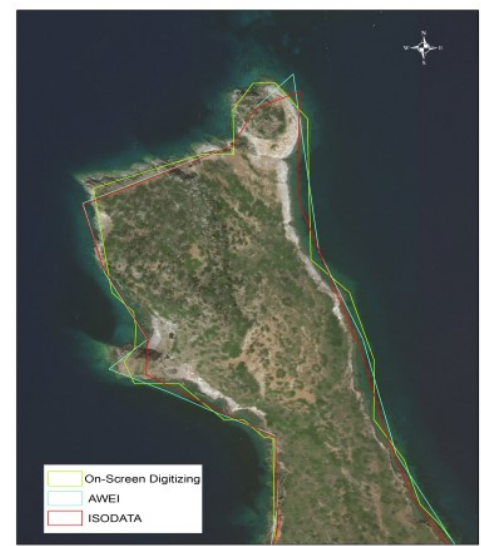

Figure 3. Visualisation of three methods differences

In large scale studies, satellite imageries which have medium temporal (16 days) and medium spatial resolution $(30 \mathrm{~m})$ are more ideal than other data sources for monitoring the coastline zone areas. Landsat 8 OLI has very great potential for coastline extraction due to having SWIR-2 (MIR) band. This is the reason of success of AWEInsh. In this paper, coastline length calculated with existing various methods has been compared with appropriate water index for Landsat 8 . In the future study finer spatial resolution can be used such as Sentinel 2 to further studies to support for testing the accuracy of multiband index due to mixed classification of non-water features. 


\section{REFERENCES}

Alesheikh, A.A., Ghorbanali, A., Talebzadeh, A., 2004 Generation the coastline change map for Urnia Lake by TM and ETM+ imagery. Map Asia Conf. 2004, Beijing China.

Niya, A., Alesheikh, A., Soltanpor, M., Kheirkhahzarkesh, M., 2013. Shoreline Change Mapping Using Remote Sensing and GIS,International Journal of Remote Sensing Applications, 3(3), 102-107.

Boak, H., and I.L., Turner, 2005. Shoreline Definition and Detection: A Review Journal of Coastal Research 2005, 688703

Cracknell, A.P., 1999. Remote sensing techniques in estuaries and coastal zones an update. International Journal of Remote Sensing 20 (3), 485-496.

Crane, R. B., 1971. Preprocessing techniques to reduce atmospheric and sensor variability in multispectral scanner data. In: Proceedings of 7th International Symposium Remote Sensing Environment Ann Arbor Michigan 2, pp 1345-1355

Dolan, R.; Hayden, B.P., and May, S., 1983. Erosion of the US shorelines. In: Komar, P.D. (ed.), CRC Handbook of Coastal Processes and Erosion. Boca Raton, Florida: CRC Press, pp. 285-299

Du, Z.; Linghu, B.; Ling, F.; Li, W.; Tian, W.; Wang, H.; Gui, Y.; Sun, B.; Zhang, X., 2012. Estimating surface water area changes using time-series Landsat data in the qingjiang river basin, China. J. Appl. Remote Sens. 2012, 6

Feyisa, G.L.; Meilby, H.; Fensholt, R.; Proud, S.R., 2014. Automated Water Extraction Index: A new technique for surface water mapping using Landsat imagery. Remote Sens. Environ. 2014, 140, 23-35.

Ekercin, S., 2007. Coastline change assessment at the Aegean Sea coasts in Turkey using multi-temporal Landsat imagery. $J$. Coast. Res. 23 (3), 691-698

Garcia-Rubio, G., Huntley, D., \& Russell, P. (2015). Evaluating shoreline identification using optical satellite images. Marine Geology, 96-105.

Göksel, Ç., İpbüker, C., Bildirici, Ö., Uluğtekin, N., 2001. "Technical Suggestion to Juridical Discussion: A case Study for Aegean Sea" ABLOS Conference, Accuracies and Uncertainties in Maritime Boundiries and Outher Limits. 18-19 October 2001, Monaco.

Guariglia, A., Buonamassa, A., Losurdo, A., Saladıno, R., Trıvıgno, M.L., Zaccagnino, A. And Colangelo, A., 2006, A Multisource Approach for Coastline Mapping and İdentification of Shoreline Changes. Annals of Geophysics, 49, Pp. 295-304.

Kafrawy, S. (2017). Monitoring the Environmental Changes of Mariout Lake during the Last Four Decades Using Remote Sensing and GIS Techniques. MOJ Ecology \& Environmental Sciences. 2. 10.15406/mojes.2017.02.00037.

Kevin, W., \& El Asmar, H. M., 1999. Monitoring changing position of coastlines using thematic mapper imagery, an example from the Nile Delta. Geomorphology, 29(1-2), 93105.
Kraus, N. C. 1988. Part IV: Prediction Models of Shoreline Change, Chapter 2, Wave Model. In: K. Horikawa, Ed., Nearshore Dynamics and Coastal Processes: Theory, Measurement, and Predictive Models, University of Tokyo Press, Tokyo, Japan, pp 324-328

Leatherman, S.P., 2001. Social and economic costs of sea-level rise. Sea-level rise, History and Consequences, B.C. Douglas, M.S. Kearney, and S.P. Leatherman, Eds., Academic Press, 181-223.

Liu, Y.; Wang, X.; Ling, F.; Xu, S.; Wang, C., 2017. Analysis of coastline extraction from landsat-8 OLI imagery. Water, $2017,9,816$

McFeeters S.K. 1996. The use of the Normalized Difference Water Index (NDWI) in the delineation of open water features. International Journal of Remote Sensing, 17 (7): 1425-1432. doi: http://dx.doi.org/10.1080/01431169608948714.

Morton, R. A. and F. M. Speed. 1998. Evaluation of shorelines and legal boundaries controlled by water levels on sandy beaches. Journal of Coastal Research 14 4:1373-1384.

Papakonstantinou, A.; Topouzelis, K.; Pavlogeorgatos, G. Coastline zones identification and $3 \mathrm{D}$ coastal mapping using UAV spatial data. ISPRS Int. J. GeoInf. 2016

Sánchez-García, E.; Pardo-Pascual, J.E.; Balaguer-Beser, A.; Almonacid-Caballer, J., 2015. Analysis of the shoreline Position Extracted from Landsat TM and ETM+ Imagery. In Proceedings of the 36th International Symposium on Remote Sensing of Environment, Berlin, Germany, 11-15 May 2015; pp. 991-998.

Smith, A. W. S. and L. A. Jackson. 1992. The variability in width of the visible beach. Shore and Beach 60 2:7-14

Wang, X.; Liu, Y.; Ling, F.; Liu, Y.; Fang, F., 2017. SpatioTemporal change detection of Ningbo coastline using Landsat time-series images during 1976-2015. ISPRS Int. J. Geo-Inf. $2017,6,68$

Winarso, G., Budhiman, S., 2001. The potential application of remote sensing data for coastal study, Proc. 22nd. Asian Conference on Remote Sensing, Singapore.

Xu, H. 2006. "Modification of Normalized Difference Water Index (NDWI) to Enhance Open Water Features in Remotely Sensed Imagery." International Journal of Remote Sensing 27 (14): 3025-3033. doi:10.1080/01431160600589179.

Xu, N., 2018. Detecting Coastline Change with All Available Landsat Data over 1986-2015: A Case Study for the State of Texas, USA. Atmosphere 2018, 9, 107 